\title{
RETRACTED ARTICLE: Vasodilatory Properties of Sacubitril/Valsartan Explored in Hypertensives Aged Over 55 Years: A Meta-Analysis
}

\author{
Renato De Vecchis ${ }^{1}$ (D) Carmelina Ariano $^{1}$
}

Received: 21 January 2019 / Accepted: 27 March 2019 / Published online: 1 April 2019

(C) Italian Society of Hypertension 2019

The editor has retracted this article [1] because it contains significant overlap with two other publications [2,3], also co-authored by De Vecchis and Ariano. This article is therefore redundant. The first, and corresponding, author has agreed to this retraction on behalf of both authors. The online version of this article contains the full text of the retracted article as electronic supplementary material.

\section{References}

1. De Vecchis R, Ariano C. High Blood Press Cardiovasc Prev. 2019. https://doi.org/10.1007/s40292-019-00313-9.

2. De Vecchis R, Soreca S, Ariano C. Cardiol Res. 2019;10(1):2433. https://doi.org/10.14740/cr813.

3. De Vecchis R, Ariano C, Soreca S. Minerva Cardioangiol. 2019;67(3):214-22. https://doi.org/10.23736/S0026 $-4725.19 .04869-2$.

Electronic supplementary material The online version of this article (doi:https://doi.org/10.1007/s40292-019-00313-9) contains supplementary material, which is available to authorized users.

Renato De Vecchis

devecchis.erre@virgilio.it

Carmelina Ariano

carmelariano@tiscali.it

1 Preventive Cardiology and Rehabilitation Unit, DSB 29 "S. Gennaro dei Poveri Hospital", Via S.Gennaro dei Poveri 25, 80136 Napoli, Italy 